\title{
ROMAN MIKULÁŠ (ed.): Metaphernforschung in interdisziplinären und interdiskursiven Perspektiven [Metaphor research in interdisciplinary and interdiscursive perspectives] \\ Leiden - Paderborn: Brill/mentis, 2020. 457 S. ISBN 978-3-95743-190-5
}

DOI: https://doi.org/10.31577/WLS.2021.13.4.14

Im Hinblick auf die fortwährende COVID-19 Pandemie stellten Francesca Panzeri, Simona Di Paola und Filippo Domaneschi in ihrem gleichnamigen Artikel die Frage: „Does the COVID-19 War Metaphor Influence Reasoning?" (vgl. Plos One, 28. 04. 2021, https:// doi.org/10.1371/journal.pone.0250651). Trägt die von Politikern und Journalisten forcierte Kriegsmetaphorik zur Erleichterung der Krisensituation bei? Oder verführt sie zu dem irrigen Schluss, dass angesichts der Gefahrenlage nur martialische Maßnahmen, inklusive Einschränkung ziviler Freiheiten und offener Autoritarismus, helfen? Der Band Metaphernforschung in interdisziplinären und interdiskursiven Perspektiven stellt sich dem Metaphern-Analphabetismus unserer Zeit vehement entgegen. Basierend auf langjähriger Vorarbeit versammelt Roman Mikuláš zwanzig Beiträge, die das weite Feld zwischen Literatur- und Medienwissenschaft, Philosophie, Pädagogik und Linguistik repräsentativ abstecken. Es geht nicht nur um die im Eingang angesprochenen rhetorischen Metaphern, die in der Rede oft als Störung des denotativen Sinnes wahrgenommen werden, sondern auch um den Umgang mit einer Sprache, die Metaphern-neutrales Sprechen kaum zulässt. Dies im Blick, äußerte Friedrich Nietzsche bereits 1873 seinen radikalen Zweifel gegenüber menschlichen Verstehensmodi: „Was ist also Wahrheit? Ein bewegliches Heer von Metaphern, Metonymien, Anthropomorphismen, kurz eine Summe von menschlichen Relationen, die, poetisch und rhetorisch gesteigert, übertragen, geschmückt wurden“ (Kritische Gesamtausgabe, hrsg. von G. Colli und M. Montanari, 1973, III. 2, 374). Wer also Metaphern erforscht, begibt sich in ein Spannungsfeld, in dem Satzanalyse und Epistemologie in enger Nachbarschaft angesiedelt sind.
In diesem Sinne spricht Mikuláš in seiner kurz und prägnant gehaltenen Einleitung den Verdacht an, „dass es so etwas wie einen allgemeinen Diskurs der Metaphernforschung gar nicht geben kann, oder dass dieser vielmehr in einem skurrilen Licht erscheint" (3). Dies ist durchaus programmatisch zu verstehen, denn die zwanzig Artikel versammeln einen buntscheckigen Haufen, der das Potential höchst unterschiedlicher Ansätze eindrücklich vor Augen führt. Die Beiträge variieren in ihrer Qualität, sind jedoch einwandfrei lektoriert.

Da maßgebliche Konzepte der Metapherntheorie in den 1960ern (Hans Blumenberg), den 1970ern (Paul Ricœur) und den 1980ern (George Lakoff/Mark Johnson) entwickelt wurden, befassen sich die wertvollsten Beiträge mit einer Umschreibung dieses in die Jahre gekommenen Kanons. Ralph Müller führt die Theorie der Konzeptuellen Metapher ad absurdum, indem er ein Rilke-Gedicht seiner metaphorologischen Reduktion der scheinbar relevanten Formel (in obligatorischer Lakoff'scher Großschreibung) GUT IST OBEN gegenüberstellt. Der blinden Anwendung des Ansatzes von Lakoff und Johnson tritt Müller entschieden entgegen: „Während aber [diese Prinzipien] für konventionellen $\mathrm{Me}$ tapherngebrauch angemessen sein mögen, kann man in stilistisch anspruchsvolleren Texten der Lyrik Beispiele finden, die gegen eine allgemeine Geltung dieser Prinzipien sprechen. Damit sind diese allerdings noch nicht widerlegt. Vielmehr scheint es, dass Texte strategisch gegen kognitive Prinzipien verstoßen können“ (46). Beatrix Fehse weist in ihrem Beitrag auf die doppelte Erfindung des Rads hin: nämlich zuerst durch Harald Weinrichs Analyse literarischer Metaphern 
und Metametaphern, dann durch Lakoff/ Johnson, die einen ähnlichen Ansatz für die Alltagssprache entwickelten. Fehses aus Weinrich und Lakoff/Johnson synthetisierter Ansatz wird anhand eines Aquarells Anselm Kiefers erprobt, womit sie einem typischen Hang zur Reduktion folgt, der weiter unten noch angesprochen werden soll. Rüdiger Zill geht einer Vergessensgeschichte metaphorologischer Reflexion nach, indem er Charles Taylors Studie The Language Animal (2016) nach ihren unausgewiesenen Anleihen bei Blumenberg und Max Black befragt.

Hochaktuell sind die beiden diskursgeschichtlichen Studien von Alexander Ziems und Andreas Brenneis. Ziems befasst sich mit Metaphern in der Diskussion kapitalistischer Mehrwertproduktion. Hier fiele auf, dass sich der Umgang mit dem kreativen Potential dieses Bildspenders „Wachstum“ seit den 1980ern gewandelt habe. Fänden sich damals noch „morphologisch kreativere sprachliche Prägungen, so Ausdrücke wie Nullwachstum, Wachstumsalternativen, Wachstumsvarianten, Wachstumsgläubigkeit und Wachstumsmöglichkeit", zeigen Kompositabildungen aus dem Jahr 2003 eine Veränderung: „Der Diskurs wird ideologisch verengt und bekommt eine neoliberale Prägung“ (165-166). Die konzeptuelle Metapher MEHR IST OBEN setzt sich somit durch. Brenneis' Beitrag erweitert die Metaphernforschung um eine diskursanalytische Anwendungsebene. Die Verschränkung von Blumenberg und Foucault erlaubt einen frischen Blick auf das Historische Apriori: Fortan gilt es, die Spezifik bestimmter Diskurse aus ihren Lieblingsmetaphern heraus $\mathrm{zu}$ entwickeln. Ob allerdings das angesprochene Großprojekt einer positivistischen Metaphorologie (211) realisierbar ist, darf getrost bezweifelt werden! Thomas Eders reiches Material zur Verwendung der Tumor-Metapher schließt nahtlos an Brenneis' Theoriebildung an, und reißt mit dem Hinweis auf die Ambivalenz politischer Bildsprache eine wichtige Frage an. Kann ein und dieselbe Metapher (z. B. EIN STAAT IST EINE FAMILIE) so unterschiedliche Verhaltensnor- men abrufen, wie sie von US-Republikanern und Demokraten vertreten werden, muss daraus folgen, dass Metaphern keinesfalls auf reduktivem Weg beseitigt werden dürfen. Sie sind der innersprachlichen différance unterworfen, welche die saubere Scheidung in Quell- und Zieldomänen aushebelt. Andrea Mikulášová und Roman Mikuláš veranschaulichen diese Beobachtung in ihrer Studie des Krankheitskomplexes, der sich durch das Werk Thomas Bernhards zieht: Krankheit sei genauso Ursprung aller Leiden wie Existenzquelle und Erleichterung. Konzeptuell verwundert, weshalb Metaphern einerseits so widersprüchliche Deutungsangebote machen, andererseits auch nie alles bedeuten können.

Solche gewichtigen Beobachtungen werden von jenen Beiträgern konterkariert, die einem vereinfachenden empiristischen Ansatz verpflichtet sind. Obwohl die Substitutionstheorie mehrfach als unzeitgemäß herausgestellt wird (u. a. in den lesenswerten Beiträgen von Juliana Goschler und Vanessa Albus), folgen diese Autoren und Autorinnen einem Ansatz, der Metaphernforschung als Aufruf zu unidirektionaler Sinnaufdeckung versteht. So indiziert Tibor Žilka die Metaphern in literarischen Werken von Ján Milčák und Pavel Vilikovský, um etwa zu dem Schluss zu kommen: „Aus der Sicht der kognitiven Metapherntheorie ist hier der VATER und seine Funktion in der gegenwärtigen Familie durch (veraltete) TECHNIK [...] und durch alte Automodelle (Trabant, Skoda) ausgedrückt“ (65). Fehse (s. o.) stellt in Kiefers Aquarell die Strukturmetapher DAS Gesicht Ist eIN Berg fest; Sybille Moser erklärt Björks multimedialen Song „Stonemilker" anhand des Bildschemas BALANCE; Ulrike Schröder macht das brasilianische Lebensgefühl des jeitinho in Handgesten fest, welche die Konzeptmetapher GooD Is BAD/ UP IS DOWN ausdrücken; und Rebecca Netzel identifiziert im Begriff "Auto-Augen“ der nordamerikanischen Lakota-Sprache das mentale Modell das Auto ist ein Lebewesen. Es entsteht der Eindruck, dass oft zu schnell von einer uneigentlichen Rede- 
weise auf den eigentlichen Sinn geschlossen wird. Mitunter nimmt diese Erkenntnisweise auch präskriptive Züge an, etwa wenn Anke Beger den metapherngesättigten Erklärungsversuch eines Lehrenden kritisiert: „the professor seems to confuse source and target domain“ (362). Welchen Erkenntnisgewinn erfüllt eine Herangehensweise, die auf einen Konkretismus hinausläuft, der besagt: uneigentlicher menschlicher Ausdruck erschöpft sich in der Rückführung auf greifbare physische Prozesse? Wie der Beitrag von Mihály Szívós vorführt, kann das Prinzip der Konkretisierung noch um eine biologische Dimension erweitert werden: Hier wird die
Fähigkeit zur Metapher auf ein frühes phylogenetisches Entwicklungsstadium zurückgeführt, in dem ontologische Ähnlichkeiten zwecks Arterhaltung wahrgenommen werden.

Mit seiner Methodenvielfalt illustriert dieser Sammelband die unterschiedlichen, oft antagonistischen Epistemologien, an der sich zeitgenössische Forschung entzündet. Oder um es mit Lakoff zu sagen: MetAPHERN SIND BRENNSTOFF.

JOHANNES D. KAMINSKI Institut für Weltliteratur SAW Slowakische Republik ORCID: https://orcid.org/0000-0002-9357-1149

\section{PETER ŽIAK: Estetika naratívnych textov [Aesthetics of narrative texts]}

Nitra: Univerzita Konštantína Filozofa, 2021. 167 s. ISBN 978-80-558-1714-9

DOI: https://doi.org/10.31577/WLS.2021.13.4.15

Monografia Petra Žiaka Estetika naratívnych textov navracia do teoretickej reflexie zásadné a stále aktuálne otázky o fungovaní fikčných naratívnych textov. Uchopenie povahy fikčného naratívu predstavuje východisko skúmania čitatel'skej estetickej skúsenosti. Zážitkovost' literatúry a procesy s tým súvisiace stoja $\mathrm{v}$ popredí záujmu autora, ktorého formovalo štúdium estetiky a francúzskej literatúry na pracovisku stavajúcom na tradícii nitrianskej školy.

Práca vychádzajúca $\mathrm{z}$ prístupov štrukturalizmu, semiotiky a recepčnej teórie pozostáva zo štyroch kapitol, v ktorých autor systematicky a precízne predkladá poznatky z oblasti literárnej teórie, pričom ich aplikuje aj prakticky na texty $\mathrm{z}$ francúzskej literatúry. Na rozdiel od všeobecne prevládajúcej orientácie na obsahové a formálne vlastnosti textu sa tažiskovo upriamuje na skúmanie účinkov literárneho textu na recipienta. Neodmieta však ani samotnú textovú analýzu. Ba práve naopak. Interpretácia estetického zážitku z čítania podla neho predpokladá najskôr dôkladné porozumenie textúre fikčného textu. Kritické zhodnotenie doterajšieho teore- tického uvažovania o predmetnej problematike v tom zmysle, že autor neraz zaujme iné alebo len čiastočne súhlasné stanovisko so závermi niektorých teoretikov, svedčí jednak o komplexnosti spracovanej témy, v ktorej je podstatná tak objektívna zložka (naratívne štruktúry fikčných textov), ako aj subjektívna (pôžitok z čítania ako značne individuálna záležitost'), jednak o dobrej znalosti odbornej literatúry, invencii a odvážnom prístupe autora monografie k textu.

Prvú kapitolu monografie logicky otvára problematika fikčných svetov, ktoré autor chápe ako konštrukty fikčného textu. Usúvztažňujúc teóriu fikčných svetov (Lubomír Doležel, Thomas Pavel) s tézami mimetickej teórie si všíma predovšetkým výpovednú hodnotu tvrdení o fikčnom svete, indikátory fikčnosti a problém referencie, čo ho privádza $\mathrm{k}$ hladaniu rozdielov medzi fikčnými a faktuálnymi textami. Osobitne sa $\mathrm{v}$ tejto súvislosti venuje postaveniu mýtu a historického textu. Spolu s teoretikmi konštatuje absenciu formálnych diferenciačných znakov, ktoré by odlíšili fikčný naratív od historického, a hovorí o uplatňovaní istých konvencií 